\title{
Phronesis, authentic learning and the solution of open-ended problems in computer science.
}

\author{
MCDERMOTT, R., ZARB, M., BALLEW, W., DANIELS, M., \\ ISOMÖTTÖNEN, V.
}

2018

C 2019 IEEE. Personal use of this material is permitted. Permission from IEEE must be obtained for all other uses, in any current or future media, including reprinting/republishing this material for advertising or promotional purposes, creating new collective works, for resale or redistribution to servers or lists, or reuse of any copyrighted component of this work in other works. 


\section{Phronesis, Authentic Learning and the Solution of Open-Ended Problems in Computer Science}

\author{
Roger McDermott, Mark Zarb, \\ William Ballew \\ School of Computing Science and \\ Digital Media \\ Robert Gordon University \\ Aberdeen, United Kingdom \\ roger.mcdermott@rgu.ac.uk \\ m.zarb@rgu.ac.uk \\ w.ballew@rgu.ac.uk
}

\author{
Mats Daniels \\ Department of Information \\ Technology \\ Uppsala University \\ Uppsala, Sweden \\ mats.daniels@it.uu.se
}

\author{
Ville Isomöttönen \\ Dept. of Mathematical Information \\ Technology \\ University of Jyväskylä \\ FIN-40014, Finland \\ ville.isomottonen@jyu.fi
}

\begin{abstract}
One of the most significant changes in Higher Education pedagogy that has occurred over the past fifty years is the idea that university students should not just be taught theoretical subject knowledge but should engage with practical aspects of their course so developing the skills and professional competences that will allow them to gain successful employment after graduation. In this paper, we relate this development to the Aristotelian notion of intellectual virtue and specifically the concept of phronesis. We discuss the way in which this idea has developed from classical beginnings to the modern educational setting, and argue that the notion of phronesis, that is, practical wisdom or prudential judgement, is crucial to a range of activities which are fundamental to science, engineering and computing education. These include an understanding of what it means to engage in authentic learning and the solution of open-ended or illstructured problems. We also discuss the role the concept plays in describing key features of work-based learning. Finally, we make some comments concerning the relative value the education system places on different types of knowledge, and why an appropriate understanding of phronesis allows for a proper appreciation of contingent knowledge within the curriculum.
\end{abstract}

Keywords - phronesis; practical wisdom; authentic learning; illstructured problems; work-place learning

\section{INTRODUCTION}

In the Nicomachean Ethics [1], Aristotle argued for the existence of three forms of knowledge: "episteme" or theoretical knowledge, "techne" or craftsmanship, and "phronesis", that is, practical wisdom or prudential judgement. Historically, with some exceptions, Higher Education has tended to prioritise the delivery of theoretical knowledge, with the demonstrative sciences being given a special prominence in the curriculum. It can be argued that Engineering, which from its beginnings as an academic discipline, included a strong practical focus [2] and so suffered less than the more established subjects in this respect. While the Pure/Applied distinction found in Mathematics or the Theoretical/Experimental divide which occurs in the Natural Sciences is not as stark, there was still a tension between the analytic, "Engineering Science" attitude of the European universities and more pragmatic, practical approaches.

More recent educational approaches have also sought to incorporate the acquisition of relevant skills and competencies into the learning process, for example, as vehicles for the assessment of authentic learning, and as important ways of enhancing social goods such as graduate employability. These two aspects of educational development appear to relate to the first two types of Aristotelian knowledge, but what about the place of practical wisdom? Does phronesis play an important part in in modern subject-based curricula and, if so, is it possible to teach prudential judgement in a computing education context?

In this paper, we give a brief overview of the Aristotelian intellectual virtues and, specifically, the concept of phronesis. We outline its appearance in modern educational literature and discuss the relevance of prudential judgment in practical learning environments, especially with reference to authenticity in vocational education and workplace learning. We argue that concepts found in these educational settings can be profitably applied in the disciplinary context of computing and engineering, and discuss the application of these ideas to popular teaching practices such as the use of real-world projects and the hard task of teaching students how to address open-ended or illstructured problems $[3,4]$. The basic line of argument is this: a fundamental element of modern university-level education in any science or engineering subject is to provide learners with an authentic learning experience in the chosen discipline. This inevitably leads to participation in learning activities that closely resemble the practices found in the workplace and these often involve problems which are open-ended or ill-structured. It is important, therefore, to provide students with the capability of addressing these types of problems and this requires them to have an understanding of the underlying principles on which the problem is based, as well as the relevant technical abilities to implement a method of solution. However, these attributes are not, in themselves, sufficient to engage with ill-structured problems since they often demand that students demonstrate the capacity to make practical or prudential judgements about complex and unfamiliar issues, such as the priorities needed to 
begin to address the problem context. This is information which may only become available to the learner as the solution is being constructed and requires a process of evaluation or judgement which is based in the specific context of the problem and so is difficult to specify prior to starting the problem-solving process. We therefore argue that the skill of developing these forms of practical wisdom or prudential judgement is crucial in today's educational environment and that allowing students to engage in such practices will enhance their professional competencies and so promote their academic growth.

Given the importance claimed for this type of activity, we investigate where it could be placed within the computing or engineering curriculum and what the development of these skills would look like in a particular learning environment.

\section{Forms OF KNOWLEDGE}

While the Ethics is a fundamental text of the Western philosophical canon, it is not usually invoked as a primary source for developing contemporary educational practice. Nevertheless, a general understanding of the intellectual virtues, in the form of the basic description presented below, together with an attempt to incorporate that understanding of these qualities into a modern philosophical and educational setting, has been a consistent feature in the work of a number of prominent philosophers. Moreover, we would contend that the virtues themselves, perhaps suitably transposed into more accessible terminology, and understood in the context of modern educational ideas, do present an interesting and productive description of learner epistemology. Consequently, we first briefly describe the classical notion of phronesis before identifying ways in which modern thinkers have appropriated the terminology to describe a range of related concepts.

\section{A. The Classical Idea of Phronesis}

Aristotle devotes some considerable effort within the Nicomachean Ethics to discussing what have since become known as the intellectual virtues, of which, episteme, techne and phronesis are the most significant in an educational context. It is important at the outset to recognise that the term "virtue" is not to be understood in its modern, moral sense, but rather as a disposition that make it possible for people to think, and act in a certain way, appropriate to the situation in which they find themselves. In his discussion of these dispositions, Aristotle introduced a number of terms which distinguish what we would now call types of knowledge and form the basis of his epistemological theory.

The first, episteme is a form of propositional knowledge that is demonstrable, that is, legitimately derivable from more fundamental principles and, as such, is context independent. Given the universality of these principles, it is tempting to see this concept as a precursor of modern "scientific" knowledge, and many translations do indeed use that word. However, it is clear that, when used in its original form, there is no simple identity with ideas of post-Enlightenment "science", which simply did not exist at that point in time. Episteme aims at the attainment of timeless or universal truth, such as that found in mathematics or metaphysics, and conveys the idea of knowledge sought for its own sake.
The second intellectual virtue is techne. This describes a form of knowledge expressed in terms of craftsmanship or artistry, and so is sometimes translated, in a modern context, as "technical expertise" or "artistry". This type of knowledge has been characterised as "knowing how" to do something and, since this depends on the situation in which the action is to take place, it is context-dependent, with the production of some kind of artefact as its primary aim. Kemmis and Smith [5] state that it is the disposition to act in a true and reasoned way, relative to the standard rules of the discipline or profession involved. As such, it results in an instrumental type of knowledge, the reasoning involved being contextual and employed to achieve some known or designated outcome.

The third virtue is that of phronesis, which Aristotle defines as 'a true and reasoned state or capacity to act with regard to the human good'. It is often translated into modern language as "practical wisdom" [6], "prudence" [7] or "practical reason" [8], and differs from its theoretical counterpart in its focus on action, rather than cultivating a more passive understanding of an idea, event or object. It incorporates the capacity for moral judgment, and cognitive understanding and insight, and, significantly, results in some kind of practical outcome. It therefore underpins the capacity to develop practical understanding and the disposition to act wisely and justly within the world. Although not a moral virtue in itself, the ability to evaluate the right end in a particular situation, and so make a wise or prudential judgement, is nevertheless aligned with the moral sense and is directed towards that same objective. The result of the process of deliberation is some positive action, and, consequently, phronesis has often been described as a disposition to "do something" (praxis) in contrast to the disposition to "make something" (poiesis) which characterises the other virtue of techne.

Despite this classification system, it was realised, even in classical times, that there is some degree of ambiguity at the margins of any consideration of this kind. Some activities or professions, such as medicine or navigation, in which right judgement would appear to play a significant part, are, nonetheless, characterised classically as techne and the dispute about assignment of medical skills to which form of knowledge is still a contested issue (e.g. [9, 10, 11]). Nevertheless, from the perspective of most educational practitioners, these are somewhat esoteric debates and discussion of the classical scope and exact meaning of the terms are of limited interest. Of greater importance is the possible development and re-expression of the concept in modern education vocabulary

\section{B. Phronesis as Reflective Judgement}

In the past hundred years, the concept of phronesis has been appropriated and employed by a number of philosophers, social scientists and educationalists as an important concept in a variety of contexts, ranging from the phenomenological works of Heidegger [12], through the philosophical hermeneutics of Gadamer [13], to the virtue ethics of Macintyre [14]. In an educational setting, the concept has been applied to a number of areas. These include the task of improving teaching practices, where the notion of phronesis has been used to provide a vehicle for inferring the implied arguments that lead to particular course of action, e.g. Green [15] and Fenstermacher [16], and as a tool 
for understanding the competencies and thinking processes of both students and teachers. Central to this line of thought was the idea of "deliberation" $[17,18]$ which sees the exercise of phronesis as similar to the practice of reflective judgement found, for example, in the works of Schön [19, 20].

This emphasis on the evaluative and inferential nature of the concept is also found in the work of educational theorists such as Dunne [6] who investigated the contextual nature of judgement, i.e. what one should do in a particular situation to accomplish a particular objective or goal. This focus on situational appreciation (or "attentiveness" as Smith [21] termed it) is also found in the work of Kessels and Korthagen [22] who developed an account of phronesis which emphasised "the understanding of specific concrete cases and complex or ambiguous situations".

Phronesis, therefore, is tied into a constellation of pedagogical ideas and concepts involving the application of reflective judgement, specifically in the context of decisions about the practical aspects of solving a problem, and the evaluation of the most prudent way of proceeding. It is irreducibly contextual and, consequently, cannot be subsumed by purely procedural methodologies.

\section{The Educational Motivation for Phronetic Activities}

If we accept that it is desirable to provide students with the opportunity to develop skills which promote good judgement, then we need to create learning environments with activities that foster these evaluative or decision-making capacities. The task of developing such skills through a process of discernment and prioritisation of relevant issues, has been addressed by a number of researchers. For example, Bowden and co-workers have examined the problem in the context of Capability Theory and attempts to extend its scope to incorporate the idea of Threshold Concepts [23, 24]. In this work, they stress the need for the following elements to be prominent in any learning situation [25]:

- Students should experience open situations in which discernment is a necessary requirement of the learning process.

- There is a need for students to engage with real-word problems within their domain of study.

- Students should have the opportunity to develop trial solutions and should understand the need to reflect on the outcomes of these trials in order to develop an understanding of the strengths and weaknesses of different approaches.

- There should be appropriate feedback from teachers and other professionals about the nature and quality of student engagement in the educational processes that lead to learning. These include ideas around reflective judgement such as discernment and diagnosis, as well as the more common elements of the design and implementation of methods of solution.

- Finally, there should be formal assessment of the processes of learning, not just the outcomes, and this should be done in a way that integrates knowledge and skill acquisition across the curriculum.

If one reads these criteria alongside more familiar educational proposals that arise from the work of Schön $[19,20]$ or Kitchener and King [26], it is reasonably clear that there is some degree of similarity and synergy between the modern conceptualisation of phronesis and the notion of reflective judgement. In addition, if, for example, we consider the above set of requirements for developing educational environments and activities that promote skills in judgement alongside workbased learning (WBL) research (e.g. Boud and Solomon [27]), we see that there is also a strong connection with ideas that emerged from consideration of authentic learning. This should come as no surprise as the relevant criteria used for making judgements about processes, or evaluating artefacts, will draw heavily on those that are set by experts, and, in a subject that has a strong work-based element, these will be determined by mature practitioners working in the field.

\section{JUDGEMENT AND AUTHENTIC LEARNING}

The description given above of the development of learning environments which promote phronesis are very similar to those which aim at providing "authentic" learning experiences for students. therefore, before looking in more detail at phronesis in a work-based learning environment, we give a brief account of authenticity which illustrates this and helps to motivate the investigation of phronesis in the context of workplace learning.

The conceptual antecedents of the idea of authenticity, understood as an important element of a pedagogical theory, can be found in the work of Brown, Collins and others, e.g. [28, 29] on situated knowledge and cognitive apprenticeships. From their perspective, in order to enter into the practices of a particular profession or community of practice, the learner needs to assimilate the behaviour and values of that community. This is essentially a type of enculturation in which the student appropriates the attitudes and practices of the community by identification with its more experienced and proficient members. Situated learning therefore required the development of knowledge and skills in contexts that reflect the way in which that knowledge will be useful in real life [30]. This approach was later elaborated and extended in the work of Lave and Wenger on the social context of learning, e.g. [31]. Similarly, the concept of authenticity was being used by Archbald and Newmann [32, 33 ] in the context of developing and aligning curriculum, teaching and assessment practices with real-world activities. Authenticity in the learning process arose partly out of this realworld correspondence, but also involved a constructivist approach to learning and the development of proficiency in the normative process of enquiry within the discipline. This, in turn, built on the learner's prior knowledge within the subject area in question.

This model of authentic learning was influential and, for example, informed subsequent developments of the concept such as that of Shaffer and Resnick [34] who argued that student perceptions of authenticity were linked to the alignment between the learning process and meaningful elements of the curriculum. These included: 
- A learning experience that was personally meaningful to the student,

- A "real-world" context outside the immediate classroom environment,

- Learning that provides an opportunity for students to "think in the modes of a particular discipline",

- An operational view of authenticity in which the assessment process reflects the learning process.

Shaffer and Resnick argued that this "thick" view of authenticity allowed for a fuller understanding of the nature of authentic learning and by doing so, reiterated views about the context in which authenticity was likely to be perceived. It is also worth noting the similarities between the description of an authentic learning environment, that is, one where authentic learning is promoted, and the description of an environment in which good judgement is promoted [25]. In both cases, there is an emphasis on learning using real-world scenarios. There is also a focus on the dynamic process of learning, described either in terms of devising and evaluating trial solutions to problems, or thinking in the modes of the discipline. It is interesting to observe that both of the aspects of authenticity connect with the practice of addressing open or ill-structured questions within the course of study.

While the idea of authenticity is certainly appealing from an educational perspective and can be used to motivate learning, particularly in practical contexts, there are issues about how it relates to assessment practices, especially in those situations and environments where it would be expected to be most useful, such as workplace learning. Before investigating the application of ideas about phronesis to the type of open-ended or illstructured problems found in work-based learning situations, we make a small digression to consider the assessment of authentic learning and the related concept of authentic assessment.

\section{Authenticity IN THE Assessment Process}

Authenticity in the assessment process is clearly a significant issue for educators and most modern learning approaches attempt to address this concern. In the context of work-based learning, it is interesting to recall that the etymology of the word assessment derives from the Latin verbal construction ' $a d+$ sedere' - to sit down beside - and therefore appears to connote a model of appraisal which is closer to that of mentorship, providing guidance and feedback on the knowledge and skills that have been learnt. With the advent of the modern university system and, certainly, with the societal changes that drive mass higher education, this mentorship model has been pushed into the background. Nevertheless, in recent times, almost all educational theorists who address the purpose and practice of assessment have recognised its importance for learning, e.g. see Boud [35, 26].

So, for example, the intimate link between assessment, student learning and performance not only forms the main idea behind the constructive alignment programme of Biggs [36] but also features as a central component in educational theories which developed from the work of Bandura [37] on selfefficacy.
Some degree of caution should be noted here when discussing ideas of authenticity in the context of learning and assessment. Cumming and Maxwell [38] noted that an interesting semantic shift occurred in the wider discussion that took place around the concepts of achievement and assessment and the relationship of these ideas to the notion of authenticity. At some point, "assessment of authentic achievement", which places an emphasis on an appraisal of the authentic nature of the achievement or the learning, evolved into 'authentic assessment of achievement' which places an emphasis on the manner of assessment and could leave the nature of the achievement itself unexamined. This is not to deny that "authentic assessment" is a valid and important concept which deserves to be the subject of academic study, but there is certainly a difference in the meaning of these phrases and they should not be confused.

If one examines the process of assessment, the focus adopted has a substantial impact on both the teaching and the realisation of intended learning outcomes [39]. A key observation is the fact that assessment tasks serve to signal curricular priorities to students. Authentic assessment tasks therefore function as mechanisms for academic and professional regulation through which the community of practice, in the form of the assessor, can direct the attention of students to prescribed content areas and modes of disciplinary thought, especially decision-making processes.

Conversely, the assessment tasks need to take account of the context of learning as well as the operational details of the teaching process. This can be particularly challenging in modern educational settings, where both teacher and student are often compelled to direct their efforts to the satisfaction of assessment goals for non-academic, institutional reasons, regardless of whether these promote learning in the most effective way. A close alignment should therefore exist between teaching processes, learning goals, assessment procedures and learning and achievement [36].

Cumming and Maxwell identified four different interpretations of authentic achievement and assessment based upon the different approaches to learning and teaching and different understandings of epistemological and pedagogical fundamental concepts. Specifically, they argued that the main conceptions of assessment were based on performance, situated learning and situated assessment, what they called "the complexity of expertise" which was assessed using problembased assessment, and competence-based assessment. In each of these cases, the assessment is used, in part, as a normative mechanism to provide students with opportunities to exhibit proficiency, not only in the technical aspects of the learning, but as a way of demonstrating nascent professional or preprofessional identity [40]. This includes such behaviours as thinking in the relevant modes of the discipline as well as espousing the values and norms of the profession. These are activities in which students which rely on the application of their prudential judgement about the profession and how it is lived in a concrete, situated context.

It should, of course, be recognised that authenticity is a much broader concept than that discussed here in the context of assessment. The exploration of the concept of authenticity has a long history in philosophy and education. Splitter [41] cites it as 
'one of those 'central, common but contestable' concepts which cry out for continual reflection and (re)examination". Philosophical and, later, psychological, interest in the concept is also strong, e.g. [42, 43, 44]. Taylor [45] summarises the ethical concerns of authenticity stating that "this notion gives a new importance to being true to myself. If I am not, I miss the point of my life; I miss what being human is for me." While these philosophical ideas about authenticity are extremely important and do, in fact, relate in a fundamental way to the wider issues of phronesis in the virtue ethics tradition inspired by Aristotle, they are not our main concern here. Instead, we turn our attention to an education setting in which the use of phronesis would be of vital importance.

\section{The SOlution Of ILl-Structured OR OPEn-ENDED PROBLEMS}

So far, we have described a network of ideas starting with the classical notion of phronesis, moving through the educational imperative to enhance the practice of reflective judgement and identifying similar ideas which appear in the context of authentic learning. The element of "situatedness" which appears to some extent in consideration of all of these concepts will be discussed in the context of work-based learning. However, before we do this, we mention one further area in which practical judgement would be expected to play a significant role, that of the solution of ill-structured problems. The reason for this is straightforward. While well-structured problems usually give rise to convergent methods of solution, directed towards some unique set of values, ill-structured problems require a more nuanced appreciation of the process by which solutions are generated and a greater degree of justification of the answer. Indeed, while the development of the capacity for justification is important in any problem-solving activity, the process of doing this for a well-structured problem has been found to be qualitatively different to that used for an ill-structured problem. Solution of the former type of problem is mainly concerned with the development of logical arguments in support of the correct solution. However, this skill has been found to be independent of performance on ill-structured tasks [46]. The justification process for ill-structured problems requires an understanding of the fact that the target in the solution space is an optimal answer rather than correct solution, and that optimality is based on the solver's ability to choose between multiple alternatives, which may be based on a variety of different perspectives

While acknowledging that the distinction between wellstructured problems and their ill-structured counterparts is not itself well-defined, and that such problems lies on a continuum, Voss [47] nevertheless provides a useful characterisation of the properties that distinguish examples of the two different types of problem. His starting point is that ill-structured problems are often stated in vague or ambiguous terms, requiring considerable explication or refinement to clarify the nature of the difficulty. The parameters that delineate the problem are not explicitly stated in the specification, requiring the solver to return to an examination of these constraints during the process of solution. There is also an iterative component to the process which involves finding a relevant representation of the problem, in addition to the technical component of applying appropriate methods of solution. This procedure often depends of the characteristics of individual problem-solvers, e.g. their epistemological or ontological beliefs [48, 49, 50, 51]. Consequently, there is no unique procedural trajectory to an answer within the problem space, and the process of solution generally gives rise to an iterative approach involving the modelling of the system (problem representation) followed by solution search. Both the problem representation and the method of solution may vary considerably between individuals. Moreover, the solution itself is typically to be assessed in pragmatic terms given some predetermined criteria of acceptability rather than being classified as either correct or incorrect, adequate or inadequate. However, the determination of the adequacy of the solution will typically itself be open to question and so any evaluation is subject to challenge. This means that the solution is stated in terms of levels of plausibility, and agreement or disagreement is more relevant than any identification of truth or falsity. There is, consequently, a process of rhetorical justification involved which is intrinsic to the method of solution. It also means that the solutions of illstructured problems are rarely, if ever, final, but are contingent on the circumstances which give rise to the problem statement. If these circumstances are themselves subject to change while the problem is in play, then implementation of any solution would need to be amended and subject to further evaluation. This open-endedness, or recognition of contingency, is an important characteristic. There is, therefore, an uncertainty about when a solution has been reached and this means that straightforward simulation of the problem can be extremely difficult or even prohibitively expensive.

From this description of ill-structured problems, it is evident that the exercise of judgement plays a key role in any method of solution, and the development in this evaluative or inferential competence is a significant component in learning to represent and engage with such problems. This can be clearly seen in the context of work-based learning where learners are often put in positions in which the problems are ill-defined and open-ended, or depend upon the exercise of "professional" judgment about a course of action.

\section{PHRONESIS IN A WORK-BASED LEARNING ENVIRONMENT}

The development of the capacity for phronesis is certainly not exclusive to the setting of work-based learning. If we consider the elements that cluster around the concept, it is clear that they include things like contextual judgement and the evaluation of the options and priorities necessary to accomplish complex tasks. These activities are contextual in the sense that the state of the system under investigation may have a direct or indirect impact upon the process of solution through a variety of feedback mechanisms. Relevant skills that would contribute to the solution of problems in this domain would include critical thinking and the ability to reflect upon the working environment. This situation describes a range of different learning situations which can be found in both traditional and non-traditional university settings and so it could be argued that it would be possible to develop the facility of phronetic judgement outside a work-based learning environment. This may well be true but from the perspective of ensuring authenticity in the learning process, this would seem somewhat contrived. 
It is true that elements of work-based learning, such as work placements or real-world projects, are now relatively common ways of engaging students with the more practical elements of their course and enhancing student employability, and these do provide opportunities to exercise the capacity of judgement. While the definition of what counts as WBL may depend upon the particular situation, we take it to include the type of learning environment that is informed by professional practices, and use the common characterisation of work-based learning as "any learning that is situated in the workplace or arises out of workplace concerns" [52]. Nevertheless, while drawing this boundary quite wide, there are still distinctions that can be made. We can, for example, distinguish between the original conception of work-based learning (e.g. [53]), workplace learning [54], work-integrated learning [55], and work-related learning [56]. The formulations of these are all slightly different with varied emphases. It is interesting to note, however, that some conceptions of work-based learning, especially those created early on in the development of the concept, were originally more transformational. Boud [26], for example, envisaged a situation in which students would "undertake study for a degree or diploma primarily in their workplace and their learning opportunities [would] not [be] contrived for study purposes but arise from normal work."

Workplace learning is an interesting context in which to consider the concept of phronesis but it might be asked why we wish to raise this issue here. One response to this question is to note Kinsella [57], who, following Schön, states that professional practices are inevitably interpretive, that is, justificatory, practices. A central concern of professional activity is how to make correct judgements which are informed by reflection. If this is so, then the basis on which such judgements are made is of prime importance when investigating how professionals act in the workplace setting. Moreover, even if we consider examples of real-world activities within a university context rather than a work-based environment, the authenticity of these tasks depends at least partly on the fact that students are engaging in the modes of thinking and acting in the discipline. Authentic learning in such circumstances is therefore tied to the exercise of reflective, phronetic judgement.

This can also be seen in the context of employability. According to Hinchliffe and Jolly [58], employers do not simply expect that graduates are able to process complex information in a procedural way, they presume they can also demonstrate cognitive maturity, exhibiting characteristics such as resourcefulness and working independently. There is an expectation that they can engage in problem-solving activities, and specifically, be able to defend any conclusions that are drawn and provide clear recommendations to others based on identifiable evidence. If this is so, then there is a general requirement for students to be given opportunities to justify their beliefs and make critical judgements in a professional manner. The workplace, or a simulation of this in the context of a realworld project, would appear to provide just such an opportunity.

\section{EXAMPLE APPLICATION AREA AND DISCUSSION}

Given the argument that an emphasis on phronesis prudential judgement - should be a key feature of the higher education system, it is interesting to examine situations in which it appears as a constituent element in the learning programme. From previous discussion, concepts of examination, evaluation and justification should appear in those subjects in which design considerations play an important part. One example of this in an informal learning setting is the Hackathon concept [59, 60] which typically involves groups of developers assembling in informal groupings to engage in intensive sprint-like collaborative activities. Some effort has been made to extend this to a quasi-formal university environment while retaining the emphasis on student control and real-world application. One such example is a bachelor-level project-based course unit presented in the Department of Mathematical Information Technology in the University of Jyväskylä in Finland. This was a 12-week, 5-ECTS project course in which small groups of students conceived, designed and implemented software prototypes that made use of open-data sets and open APIs (Application Programming Interfaces) to create new, innovative services or applications. It was added to the curriculum in order to pave the way for a master-level industry-strength software project for real customers. The course unit aims were to increase student understandings of software process, project management issues, and group work, as well as to introduce them to questions surrounding intellectual property rights. The course was an option for a bachelor level practical course and was taken by 15 26 students each year (with this cohort split into groups of four students).

In this particular course unit, the groups were first made aware of the existence of various open resources on the web and then asked to develop and iterate project ideas by considering matches between personal interests and intentions, available data and APIs, and potential target groups. The resultant project ideas were presented after 2-3 weeks in a session where the groups receive feedback from peers and supervisors. The course unit is scaffolded with the inclusion of taught input on group concepts (fairness, statutes, roles, norms, and typical behaviour patterns anchored to these concepts) and the software process. Throughout the course unit, the development groups were required to work independently, scaffolded by short regular meetings with a teacher in charge and a senior student who provided technical guidance. These meetings took place on a weekly basis and allowed discussion of emergent issues in group work and software processes. During the course, an expert lecture on intellectual property rights (IPR) was also provided. Groups presented their products during a day of final presentations in their project rooms to which faculty students and staff members were invited. The visiting audience was then given the opportunity to test project deliverables and discuss students' project experiences. Passing the course required active participation with the minimum of 100 individual work hours reported, and a personal end-of-course learning report.

This type of open-ended course unit demonstrates a learning environment in which self- and group-regulation are key elements in the success of both the project and the learning process. Groups are required to make decisions about aspects of technical support and project management. They make requests for faculty computing support regarding issues such as hardware and software installation, choice of programming languages, and project management tools. The make-up of the development team, the assignment of roles and the development process is, to 
a certain extent, also open with alternatives and further scaffolding presented. The software process is addressed at a conceptual level by emphasising principles such as commitment and situation awareness, and by discussing and conceptualising issues that arise during the project process. The desired course attributes (creativity and ill-formedness, and open-endedness), allow students take responsibility of project features, emphasise self-reliance.

What features of this type of learning environment relate to the concept of phronesis or promote reflective or prudential judgement? Clearly for students to be successful in this situation, they need to exercise a number of personal attributes relating to individual learning, group working and There are a number of general capabilities which need to operate in order to perform well in this type of open-ended or ill-structured environment. Some of these relate to technical or interpersonal skills, which are clearly important when undertaking groupwork of this kind. However, if one examines what one might term the (intra) personal attributes needed to successfully complete this type of task, we believe that they can be broadly classified into two separate but connected areas - a metacognitive capability for self-regulation of learning $[61,62]$ within the learning environment, and a psychological disposition for self-reliance. The former underlies the cognitive abilities for self-direction and, ultimately, self-efficacy [37]. Zimmerman describes the cycle of phases of self-regulation in terms of forethought or planning, performance and self-reflection. In each of these, we see applications of phronetic activity: goal setting and strategic planning in the forethought phase, attention focussing in the performance phase and self-evaluation in the self-reflection phase. In each of these case, the learner needs to make practical judgements based on their knowledge and experience in that situation. Goal setting relies on the ability to discern what is appropriate, attention focussing on the ability to judge what is important, self-evaluation on the capacity to reflect on context and make suitable judgements about personal performance and how this can be moderated. In that sense, we would contend that phronesis is a fundamental underpinning of these processes.

The second personal attribute is linked to the conceptions of resilience and self-reliance. Recent research has tended to characterise these concepts as manifests as manifestations of perseverance or persistence in terms of "grit" [63] or academic tenacity [64]. Duckworth defines grit as "the disposition to pursue long-term goals with sustained interest and effort over time" and considers it to be distinct from other traditionally measured facets of conscientiousness by its emphasis on stamina. In particular, grit entails the capacity to sustain both effort and interest in projects that take months or years to complete. Writing from a perspective of Self-theory, Dweck uses the term "academic tenacity" to denote a similar quality of self-reliance which manifests itself as "a mindset that looks beyond short-term concerns to longer-term or higher-order goals, and so withstands challenges and setbacks to persevere toward these goals". Dweck's emphasis on learner mindsets not only brings together aspects of personal epistemology with identity theory, but also considers the skills that are needed to overcome challenges and setbacks. One question which could be asked is what happens if a learner decides, say, that it is more prudent to not persist on a problem? Would this not entail prudential judgement being used to diminish a successful outcome? An Aristotelian response to this would be that a beneficial attitude or strategy, i.e. a virtue, is not seen as being a polar opposite to a single detrimental strategy - vice - but are rather seen as taking a mean between vices of excess and deficiency. So, a good behaviour such as perseverance, lies in the "Goldilocks zone" [65] between too little effort and too much, and of course, it is a matter of prudential judgement whereabouts on that spectrum this is.

In both these cases, an underlying presupposition for the concept to be relevant and applicable in an educational context is that the learner has the ability to recognise beneficial strategies and act on them. This is, in essence, an application of phronesis, involving as it does, the integration of medium and long-term goal-seeking strategies and evaluative reasoning about priorities. In this context, it is worth reviewing the conclusions of Beecham et al [66] who address the question of whether the learning activities undertaken by software engineering students correlate with actual practice in a global software development team, especially within a small or medium-sized enterprise (SME). They report that global software engineering education, while providing technical content, still falls short of providing students with the skills in project management, interpersonal and leadership skills necessary to manage the collaboration processes which are part of the discipline, and this is accentuated in the context of an SME where there is greater fluidity in employee roles and responsibilities. They conclude that it will be necessary to develop approaches which "[wean] students off reliance on their instructors and [enable] them to take more active ownership of the course design and operation as an integral part of their learning".

\section{CONCLUSION}

In this paper, we have sought to show that the concept of phronesis, developed in classical times to describe the disposition for practical wisdom and prudential judgement, remains an important element of the educational process. Moreover, the exercise of this disposition through the activity of reflective, contextual judgement is a fundamental component of a range of developmental pedagogical approaches. These seek to provide an authentic learning experience for students, in which they may begin to participate in the communities of practice of the professions. We have also attempted to trace a link between the idea of authentic learning and its expression in the solution of ill-structured problems which require the use of evaluative or interpretive judgements. The use of such judgements, and the requirement to justify action based on them, are ubiquitous features of work-based learning environments. We have also given a small but illustrative example of where this type of activity is being practiced.

Hinchliffe and Walkington [67] state that an important aim of university education is getting students accustomed to make, defend and criticise such judgements. This has an epistemological benefit in that it demonstrates the contingent nature of knowledge but also provides the students with the opportunity to take responsibility for those judgments and consequent actions. If universities wish students to make a successful transition to a working environment in which they are expected to demonstrate the capability of making and defending 
judgements, then they must be presented with opportunities to develop that skill and so provision for it must be built into the curriculum.

One final relevant comment may be made about the sense of value that society as a whole, and academia in particular, places upon certain types of knowledge. In his essay, "Why we need a philosophy of engineering: a work in progress", the philosopher Steven L. Goldman (2004) suggests that the type of problems solved by engineers are qualitatively different from those solved by scientists or mathematicians. Goldman contends that the Western philosophical tradition has generally tended to elevate universal, context-independent, "scientific" knowledge at the expense of context-dependent, contingent, situational knowledge. This is reflected in the privileged, epistemic status of the mathematical sciences when compared, say, to the engineering disciplines. The pursuit of certainty or universality, which is a feature of the scientific approach is not necessarily shared by engineering which works with contingent knowledge and has a focus on practical and pragmatic action. Clearly, scientific expertise is used in the creation of engineering artefacts and the solution of engineering problems, but the underlying philosophy of the subject is different and is based on a concept of design within a pragmatist framework.

There are some parallels between this discussion and the distinction between episteme and phronesis, made earlier. Historically, for the most part, the educational remit of universities was to provide students with theoretical knowledge, even in a comparatively new discipline such as Computing. The development of curricular models based on ideas of competency has served to bring a more practical approach to subjects. However, techne - technical skill - while necessary must be accompanied by the ability to make appropriate practical, prudential and reflective judgements. Consequently, the opportunity to make such judgements should be an identifiable part of the computing and engineering curriculum. The more widespread use of embedded pedagogies, such as work-based learning in all its manifestations, provide opportunities for students to exercise their faculties of judgement but these ae not exhausted by work-based learning and the real challenge may be to incorporate this type of activity in more traditional learning activities.

\section{ACKNOWLEDGEMENTS}

The authors would like to thank the anonymous referees for extensive, helpful suggestions on how to improve the paper.

\section{REFERENCES}

[1] Aristotle. Nicomachean Ethics. Irwin T, tr. Cambridge: Hackett Publishing Company, 1985.

[2] Seely, B.E., The Other Re-engineering of Engineering Education, Journal of Engineering Education, Vol. 88, No. 3, 1999, pp. 285-294.

[3] Simon, H.A., 1973. The structure of ill-structured problems. Artificial Intelligence 4 (3), 181-201.

[4] Jonassen, D. H., 1997. Instructional design models for well-structured and ill-structured problem-solving learning outcomes. Educational Technology Research and Development, 4(1), 65-95.

[5] Kemmis, S., \& Smith, T. J. (Eds.). 2008. Enabling praxis: Challenges for education. Rotterdam: Sense.
[6] Dunne, J., 1993. Back to the rough ground: "Phronesis" and "techne" in modern philosophy and Aristotle. Notre Dame, IN: University of Notre Dame Press.

[7] Jullien, F., 2004. A Treatise on Efficacy: Between Western and Chinese Thinking. University of Hawaii Press, Honolulu.

[8] Wiggins, D., 1980. Deliberation, and practical reasoning. In Ror- ty, A., editor, Essays on Aristotle's Ethics, pages 221-40. Uni- versity of California Press, Berkeley, CA.

[9] Jonsen AR, Toulmin S., The Abuse of Casuistry: A History of Moral Reasoning. Berkeley: University of California Press, 1989: 14, 42-46, 257.

[10] Waring, D., 2000, Why the Practice of Medicine Is Not a Phronetic Activity, Theoretical Medicine and Bioethics, 21, pp. 139-51.

[11] Svenaeus, F., The Hermeneutics of Medicine and the Phenomenology of Health: Steps Towards a Philosophy of Medical Practice, 2nd rev. ed. Dordrecht: Kluwer, 2001.

[12] Heidegger, M. Sein und Zeit, 16th ed. Tübingen: Max Niemeyer Verlag, 1986.

[13] Gadamer, Hans-Georg, Philosophical Hermeneutics, David E. Linge, trans., Los Angeles: University of California Press, 1976.

[14] MacIntyre, A., 1983. After virtue: A study in moral theory. 2nd ed. London: Duckworth.

[15] Green, T. F., 1976 Teacher competence as practical rationality, Educational Theory, 26, pp. 249-258.

[16] Fenstermacher, G. D. and Richardson, V., 1993 The elicitation and reconstruction of practical arguments in teaching, Journal of Curriiulum Studies, 25(2), pp. 101-1 14.

[17] Engberg-Pedersen, T., 1983 Aristotle's Theory of Moral Insight (New York, Clarendon Press).

[18] Audi, R., 1989 Practical Reasoning (New York, Routledge).

[19] Schön, D., 1983. The reflective practitioner. New York: Basic Books. A. Z. 1989.

[20] Schön, D., 1987. Educating the reflective practitioner. San Francisco: Jossey-Bass.

[21] Smith, R., 1999. Paths of judgment: The revival of practical wisdom, Educational Philosophy and Theory, 31, pp. 327-40.

[22] Kessels, J. P. A. M., \& Korthagen, F. A. J., 1996. The relationship between theory and practice: Back to the classics. Educational Researcher, 25, 17-22.

[23] Bowden, J., \& Marton, F., 1998. The university of learning: Beyond quality and competence in higher education. London: Kogan Page.

[24] Bowden, J. A., 2004. Capabilities-driven curriculum design. In C. Baillie \& I. Moore (Eds.), Effective learning and teaching in engineering (pp. 3647). Abingdon, Oxon: Routledge Falmer.

[25] Baillie, C., Bowden, J. and Meyer, J., 2013. Threshold capabilities: threshold concepts and knowledge capability linked through variation theory. Higher Education 65: 227-246.

[26] Boud, D., and Solomon, N. (Eds.). 2001. Work-based Learning: A new higher education? Philadelphia, PA: Open University Press

[27] Kitchener, K. S., \& King, P. M., 1990. The reflective judgment model: Ten years of research. In M. Commons, C. Armon, L. Kohlberg, F. Richards, T. Gratzer, \& J. Sinnott (Eds.), Adult development: Vol. 2. Models and methods in the study of adolescent and adult thought (pp. 6378). New York: Praeger

[28] Brown, J.S., Collins, A. and Duguid, P., 1989. Situated cognition and the culture of learning. Educational researcher, 18(1), pp.32-42.

[29] Collins, A., Brown, J. S., and Newman, S. E., 1989. Cognitive apprenticeship: Teaching the crafts of reading, writing, and mathematics. Knowing, learning, and instruction: Essays in honor of Robert Glaser, pp.453-494.

[30] Collins, A., 1988. Cognitive apprenticeship and instructional technology (Technical Report No. 6899): BBN Labs Inc., Cambridge, MA.

[31] Lave, J. and Wenger, E., 1991. Situated Learning: Legitimate Peripheral Participation. Cambridge University Press. 
[32] Archbald, D.A. and Newmann, F.M., 1988. Beyond Standardized Testing: Assessing Authentic Academic Achievement in the Secondary School.

[33] Newmann, F.M. and Archbald, D.A., 1992. The nature of authentic academic achievement. Toward a new science of educational testing and assessment, pp.71-83

[34] Shaffer and Resnick

[35] Boud, D., 1995. Assessment and learning: contradictory or complementary. In P. Knight (Ed.) Assessment for learning in higher education, pp.35-48, London: Kogan.

[36] Biggs, J.B., 2003. Teaching for quality learning at university. Buckingham: Open University Press.

[37] Bandura, A., 1977. Self-efficacy: toward a unifying theory of behavioral change. Psychological review, 84(2), p.191.

[38] Cumming, J.J. and Maxwell, G.S., 1999. Contextualising authentic assessment. Assessment in education: Principles, policy \& practice, 6(2), pp.177-194.

[39] Brown, G.A., Bull, J. and Pendlebury, M., 2013. Assessing student learning in higher education. Routledge.

[40] Jackson D., 2016. Re-conceptualising graduate employability: the importance of pre-professional identity. Higher Education Research and Development 35(5), 925-939.

[41] Splitter, L.J., 2009. Authenticity and constructivism in education. Studies in philosophy and education, 28(2), pp.135-151.

[42] Wrathall, M.A. and Malpas, J.E. eds., 2000. Heidegger, authenticity, and modernity (Vol. 1). MIT press

[43] Guignon, C.B., 2004. On being authentic. Psychology Press.

[44] Snyder, C.R. and Lopez, S.J., 2009. Oxford handbook of positive psychology. Oxford University Press, USA.

[45] Taylor, C., 1991. The Ethics of Authenticity, Cambridge, Massachusetts and London.

[46] Schraw G., Dunkle, M. E., \& Bendixen L. D., 1995. Cognitive processes in well-structured and ill-structured problem solving. Applied Cognitive Psychology, 9, 523-538.

[47] Voss, J., 2006. Toulmin's Model and the Solving of Ill-Structured Problems. Arguing on the Toulmin Model: New Essays in Argument Analysis and Evaluation. Springer. 2006

[48] Oh, S., \& Jonassen, D. H., 2007. Scaffolding online argumentation during problem-solving. Journal of Computer-Assisted Learning, 23, 95-110.

[49] Schraw, G., 2001. Current themes and future directions in epistemological research: A commentary. Educational Psychology Review, 13(4), 451464

[50] Sinatra, G. M., Southerland, S. A., McConaughy, F., \& Demastes, J. W., 2003. Intentions and beliefs in students' understanding and acceptance of biological evolution. Journal of Research in Science Teaching, 40, 5, 510528.

[51] Greene, J. A., Azevedo, R. and Torney-Purta, J., 2008. Modeling epistemic and ontological cognition: Philosophical perspectives and methodological directions. Educational Psychologist, 43: 142-160.
[52] Lester, S. \& Costley, C., 2010. Work-based learning at higher education level: value, practice and critique. Studies in Higher Education 34 (5)

[53] Raelin J.A., 2000 Work-Based Learning. Prentice-Hall, Upper Saddle River, NJ.

[54] Billett, S., 2001. Learning in the workplace: strategies for effective practice (Sydney, Allen \& Unwin)

[55] Jackson, N., 2006. Work-integrated learning in the UK: an overview. University of Surrey: Surrey Centre for Excellence in Professional Training and Education.

[56] Maurer, T. J., Weiss, E. W., \& Barbeite, F. G., 2003. A model of involvement in work-related learning and development activity: The effects of individual, situational, motivational, and age variables. Journal of Applied Psychology, 88(4): 707-724.

[57] Kinsella EA., Practitioner reflection and judgement as phronesis. In: Kinsella EA, Pitman A, eds. Phronesis as Professional Knowledge: Practical Wisdom in the Professions. Rotterdam: Sense Publishers 2012;35-52.

[58] Hinchliffe, G., and Jolly, A., 2011. Graduate identity and employability. British Educational Research Journal, 37, 563-584.

[59] Jones GM, Semel B, and Le A., 2015. There's no rules. it's a hackathon Negotiating commitment in a context of volatile sociality. J Linguist Anthropol. 2015; 25(3): 322-345.

[60] Trainer, E.H., Kalyanasundaram, A., Chaihirunkarn, C., and Herbsleb, J.D. 2016. How to Hackathon: Socio-technical Tradeoffs in Brief, Intensive Collocation. In Proceedings of the 19th ACM Conference on Computer-Supported Cooperative Work \& Social Computing. ACM, 1118-1130.

[61] Zimmerman, B., 2002. Becoming a self-regulated learner: An overview. Theory Pract. 41, 64-71

[62] Schunk, D. H., \& Zimmerman, B. J., 2003. Self-regulation and learning. In W. M. Reynolds \& G. E. Miller (Eds.), Handbook of psychology: Vol. 7. Educational psychology (pp. 59-78). New York: Wiley

[63] Duckworth, A. L., Peterson, C., Matthews, M. D., \& Kelly, D. R., 2007. Grit: perseverance and passion for long-term goals. Journal of personality and social psychology, 92(6).

[64] Dweck, C., Walton, G. M., \& Cohen, G. L. 2011. Academic tenacity: Mindsets and skills that promote log-term learning. Paper presented at the Gates Foundation, Seattle, WA.

[65] Southey, R., 1837. The Tale of Three Bears. In in Iona and Peter Opie, The Classic Fairy Tales (Oxford UP, 1974): 264-68

[66] Beecham, S., Clear, T. and Noll, J., 2017, "Do We Teach the Right Thing? A Comparison of Global Software Engineering Education and Practice," in Proceedings 2017 IEEE 12th International Conference on Global Software Engineering D. Cruzes and A. Sharma, Eds., ed Los Alamitos, California: IEEE.

[67] Hinchliffe G., Walkington H., 2017. Cultivating the Art of Judgement in Students. In: Tomlinson M., Holmes L. (eds) Graduate Employability in Context. Palgrave Macmillan, London

[68] Goldman, S.L., 2004. Why we need a philosophy of engineering: A work in progress. Interdisciplinary Science Reviews, 29 (1), 163-176. 